\title{
Imprensa e Violência Carioca ${ }^{1}$
}

\author{
Bernardo M. Gomes Carneiro \\ Estudante de Jornalismo - UFRJ
}

INTRODUÇÃO

I! Iîndo-se em uma época na qual a violência está por toda a parte e já virou assunto cotidiano nas grandes cidades, muitas vezes não se consegue distinguir o importante papel da mídia na construção dessa realidade. A todo momento a TV, o cinema, os jornais e a música bombardeiam o público com manifestaçôes ou interpretações da agressividade e do crime. Devese questionar qual é a verdadeira intenção mediática em fazer da violência o alvo de vários de seus veículos.

É fato que os índices de violência de um centro urbano populoso como o Rio de Janeiro atingem patamares bastante altos. A vio lência é, com certeza, um dos problemas sociais mais complexos e suas causas englobam inúmeros fatores, dentre eles a má distribuição de renda, a falta de políticas públicas eficientes de combate à violência, os resquícios de autoritarismo na polícia, etc.

Pois bem, independente dos índices de violência, podemos identificar ao longo da história certos momentos em que a mídia coloca discussão sobre a questão da violência em foco. A abertura política da ditadura foi um destes momentos ${ }^{2}$. A partir de então a discussão sobre a violência vem se alternando na mídia de maneira mais ou menos intensa. No contexto político atual, podemos destacar uma intensificação desta discussão. Entretanto, sempre que a discussão sobre violência aparece na mídia ela é feita de maneira superficial, sem que se vá a fundo nas questões mais importantes.

As questões que consideramos relevantes e que consideramos serem ignoradas de certa forma pela mídia são, por exemplo, as práticas autoritárias das instituiçōes policiais, o preconceito, a hierarquização da sociedade ${ }^{3}$. A função ainda política da polícia pouco é discutida.

Outro elemento da superficialidade desta discussão é a maneira como a mídia espetaculariza a violência. Seja de forma explícita, como é o caso do jornalismo (impresso ou televisivo) sensacionalista; seja de forma maquiada, como no caso do jornalismo dito sério. Faremos uma breve diferenciação entre 0 jornalismo sensacionalista e o jornalismo chamado sério ou tradicional.

Conseqüência direta da superexposição da violência pelo jornalismo sensacionalistas é a desrealização dos fatos por parte dos leitores

I A direção da revista decidiu publicar este artigo, considerando seu profundo conteúdo social ejornalístico e conseqüente vínculo à área jurídica.

2 CERQUEIRA FILHO, Gisálio \& NEDER, Gizlene. "A violência na boca do povo"

3 Tratada na perspectiva de pensadores como o antropólogo Roberto da Matta.

Revista da Faculdade de Direito da UFRGS, v. 19, Março/2001 
ou espectadores, ou seja, passa-se a confundir o que é real e o que é imagem mesmo tratandose de notícias da cidade em que se vive. A cena reportada de violência deixa de produzir emoção, torna-se simplesmente mais um caso sangrento, quase como uma cena de cinema. A mídia, em geral, consegue muitas vezes coincidir real e imagem. Contudo, dentro da imprensa, tal poder não é saudável, pois limita a veracidade do jornalismo apresentado. Portanto, a abordagem da violência como espetáculo contínuo por certos veículos pode parecer "bom negócio" para aqueles que optam por um jornalismo sensacionalista, mas é extremamente prejudicial para a clara compreensão social da criminalidade.

Já na mídia tradicional (ou "não-sensacionalista") o que marca o tratamento dado à violência, ao contrário do "voyerismo coletivo" visto anteriormente, é a mani pulação dissimulada da notícia. De forma muito mais discreta que nos veículos já citados, estes setores da mídia utilizam-se de recursos como localização e disposição da material para dar o destaque desejado, segundo seus respectivos padrões, à questão da criminalidade. Cada uma das reportagens vem permeada de sentidos fora o da própria notícia coerentes à ideologia do meio de comunicação no qual foi veiculado. A fotografia que acompanha a notícia, o ângulo em que esta foi clicada, o que se escreve nas legendas, a sessão em que foi posta a notícia, tudo pode, e é, mani pulado para transmitir-se a idéia exata que se deseja de determinado assunto, principalmente se ele abordar a violência urbana. $\mathrm{O}$ mesmo ocorre com os diferentes ângulos de câmera, as formas de editar, os depoimentos favoráveis, quando falamos do jornalismo televisivo.

A espetacularização envolve, portanto, inúmeros fatores. Os mais evidentes são a criação de uma atmosfera maniqueísta (através da construção de uma figura do Outro, representa- do pelo criminoso) e a ocultação de uma discussão sobre as raízes do problema. O que que remos dizer é que através desta espetacularização a mídia evita discutir, enfocar as raízes mais profundas do problema da violência. Ela não coloca o porquê de um ser humano agir violentamente. A violência é, na maioria das vezes, tratada como uma prática comum ao Outro, ao marginal, àquele que é considerado excluído da sociedade. É como se a sociedade se dividisse claramente entre inocentes (reféns, por exemplo) e os diferentes, marginais (criminosos em potencial)

\section{VIOLÊNCIA NA MÍDIA ATUAL}

Muito se fala sobre a cobertura da violência na mídia, e da responsabilidade sobre a veiculação de notícias de guerra, crimes ou desastres. Mesmo tendo conhecimento da relação interesse popular (portanto audiência/vendas) $x$ violência (sensacionalismo e explicitação), há quem se ofenda com fotografias mais explícitas que ao mesmo tempo juntam transeuntes curiosos nas bancas ou com notícias que assustam pela banalidade com que tratam o absurdo. $\mathrm{E}$ há quem culpe a mídia por alimentar o círculo vicioso de violência (impressa ou filmada) gerando mais violência (a se filmar ou imprimir). Além de todos aqueles que vibram com a violência exposta e alimentam o número de leitores e espectadores chamados voyeurs.

Para discutir a responsabilidade da mídia ao tratar da violência, usar-se-á aqui dois discursos proferidos nos dias 12 e 13 de junho próximo passado no $53^{\circ}$ Congresso Internacional de Jornais organizado pela WAN, no Hotel Intercontinental do Rio de Janeiro. As palestras foram proferidas pelo governador do Rio de Janeiro Anthony Garotinho e pelo presidente da República Fernando Henrique Cardoso. O pro nunciamento de Garotinho ocorreu ao mesmo tempo em que duas emissoras (Record e Globo
News) de TV transmitiam ao vivo o desenlace de um seqüestro a um ônibus no bairro do Jardim Botânico, zona sul do Rio. O de FHC se deu no dia seguinte, após repercussão midiática e popular, e após declarações do próprio presidente na noite do ocorrido.

Os dois defendem pontos que se chocam. Garotinho acusava a mídia de ter atração pela violência e tratar o assunto distorcendo os fatos. Durante a palestra Uma visão oficial da violência - como a mídia deve cobrir a violência, ele mostrou números oficiais e muitos sorrsos otimistas. A mídia através de destaques criaria insegurança na população. Qualquer luga poderia esconder um criminoso que a polícia não teria capacidade de prender. $\mathrm{O}$ governador explicou o funcionamento do sistema policial e os bons resultados conseguidos. Não ex plicou porque em uma situação de seqüestro, $O$ Bope (Batalhão de operações especiais, tropa de elite da PM) e não a DAS (Divisão AntiSequestro) se encarregou de agir, no Jardim Botânico ${ }^{4}$.

$\mathrm{Na}$ verdade, o governador não tinh como explicar. $\mathrm{O}$ seqüestro acontecia ao mesmo tempo em que seu otimismo acusava a mídi brasileira de criar sindromes. Garotinho só tomou conhecimento da tragédia quando a palestra terminou. Com um sorriso desmanchado no rosto o radialista e politico num primeiro momento disse que estava com a polícia, e que a situação se contornaria. Ao fim do seqüestro ele elogiou a ação policial, apesar da morte de uma refém. Só depois de saber que os agente de elite do Bope haviam asfixiado o criminoso, resolveu tomar providências e reconhecer papel do trabalho dos jornalistas: cobrir os fatos, não encobri-los. Policiais foram afastados, investigações estão sendo feitas e acena-se com a possibilidade (de efeito duvidoso) de conta com as Forças Armadas nas ruas.
Anthony Garotinho escreveu um livro para a campanha ao governo do Rio de Janeiro. Contou com a colaboração de Professores Acadêmicos, entre eles Luís Eduardo Soares mais tarde secretário de segurança de seu governo, para tratar da violência. Produziu um retrato detalhado em cima de estatísticas para mostrar o quadro da violência no Rio de Janeiro, principalmente na capital. Percebe-se que a fatia maior da criminalidade fluminense e carioca não é noticiada: violência doméstica. A mídia portanto não estaria interessada em publicar açōes preventivas (poucas e insuficientes) policiais preferindo as grandes prisões que provocam a rotatividade de grandes traficantes no comando do crime, grandes sequestradores de quadrilhas que não se desmontam, etc.

E o livro aponta uma solução com criação do Consep - Conselho de Segurança Pública - para monitorar o funcionamento de toda asinstituições de alguma forma ligadas ao combate ao crime e da restauração da credibilidade policial junto às comunidades de alta e baixa renda. Tanto se daria com mudanças de postura policial, proximidade de ação preventiva $e$ combate ao pânico e medo com presença física além de sujeição à avaliações por líderes comunitários. Em um ano e meio de governo nada de efetivo foi produzido para o sucesso destes projetos. O sequestro do 174 talvez tivesse outro fim com a ação dos homens treinados em negociação com criminosos do DAS. O Consep saberia indicá-los.

A palestra do presidente Fernando Henrique apontou para outra direção, com um tom de divisão de responsabilidades entre população, mídia e governo. FHC defendeu que a imprensa tem o dever de informar, portanto tornar de conhecimento público os acontecimentos sem se esconder ou sem criar uma situação. O sociólogo revelou que busca através de seu

${ }^{4}$ KRAMER, Dora. "Erro de pessoa" in Jornal do Brasil (coluna Coisas da política). 17/06/2000. 
governo e de seus relacionamentos viabilizar a construção de 'espaços democráticos' ${ }^{5}$ no Brasil. Por isso partici pava da palestra Democraci na Era Digital (havia outros membros à mes debatendo a liberdade de imprensa). Também por isso defendia o trabalho dos jornalistas que cobraram melhor performance das políticas de segurança e a presença de uma polícia preparada para lidar com incidentes de risco para a sociedade.

O presidente lembrou que a Internet traz um número maior de pessoas à democracia. mídia, enquanto responsável pela formação de opiniões, deve ter liberdade de ação e só pode ser criticada através de seus meios/veículos. Qualquer outra forma de crítica ou retaliação fere o processo democrático. O papel da população é de regular a imprensa, e interagir no processo de tomar decisões. No que se entend hoje como democracia, a mídia desempenha a função de divulgar e revelar questões em debate para todos os grupos sociais interessados, a fim de abranger a troca de idéias. Com a Internet esse processo se abre ainda mais atravessando barreiras geográficas. Na nova ordem mundial, uma ditadura com controle de informações fura a lógica social. A imprensa (livre) fundamenta a democracia moderna.

A violência, portanto, precisa se noticiar para buscar a discussão da segurança pública para avaliar questões sociológicas, psicológicas da contemporaneidade. Quando ela é simplesmente um atrativo com fins lucrativos, a sociedade deve reclamar através de outros meios de comunicação ou boicotar o produto. A publicidade influi também na produção e manutenção de programas jornalísticos (independente do meio) através de pesquisas que provam que a vinculação do produto com o teor credibilidade das matérias pode não vender 0 produto. Isso já acontece: por exemplo, com a

reformulação recente do programa Cidade Aler ta da TV Record, que viu-se obrigado a mudar o tom das notícias devido às quedas no índice de audiência. O programa continua 'popular', mas não utiliza mais a polícia como fonte e não permite mais que o apresentador Datena se exalte exigindo violência da polícia no combate ao crime. A mudança editorial de jornais como $O$ Dia e mais recentemente $O$ Povoreforça a tese.

Portanto, concluiu-se que a violência se encontra na mídia por necessidade (vivemos em uma democracia, ou pelo menos em busca de) mas que existem formas de abordagem melhores que outras. $O$ sensacionalismo da violência não possui público fiel, então os veículos que escolhem adotá-lo acabam, com o tempo, tendo que mudar a linha editorial para se consolidar. E mesmo veículos já consolidados cometem erros. Analisar-se-á a seguir o caso Rodney King, ocorrido nos EUA, provocador de uma série de mudanças na cobertura jornalística americana e o caso recente do seqüestro do ônibus 174 no Rio de Janeiro, o primeiro com cobertura de um portal de Internet no país, $e$ com diferentes coberturas por parte de um canal de TV aberta e um de TV a cabo. A Rede Globo optou por não cobrir o incidente ao vivo, apenas com plantões, para não mostrar um assassinato ao vivo em rede nacional, segundo um diretor de jornalismo da emissora.

\section{Rodney King}

Através de uma câmera amadora, a população dos Estados Unidos tomou conhecimento em 1992 de um espancamento nas ruas de Los Angeles. Policiais brancos usavam de forte violência fisica contra um jovem negro, Rodney King. O vídeo amador, produzido por um cidadão comum, foi entregue a uma estação local que transmitiu as imagens, retransmitidas por outras emissoras repetidamente. Inclusive a CNN teve acesso às imagens - tornando-as internacionais.

A situação foi muito explorada pelos meios de comunicação: um negro agredido covardemente por policiais brancos. O chefe de polícia de LA tinha grande populari dade e prestígio político. Tratava-se de uma grande situação para o trabalho da mídia, para as finanças das empresas de comunicação.

No início, a repetição do vídeo e as cobranças faziam sentido, possuíam um propósito. No entanto, o discurso que se formou para tratar da questão R.King começou a ganhar are de campanha contra a polícia de LA. Os jor nais americanos criaram tensão na comunidade negra e passaram a pressionar autoridades policiais usando depoimentos muitas vezes desastrados dos responsáveis.

Um caso que talvez não ganhasse repercussão ocorreu então em meio à situação, tavez em função do imaginário social de medo que se criou. Uma comerciante coreana atirou em uma menina negra de 15 anos, pensando que a menina tentava roubar alguma coisa. Condenada e julgada, a mulher recorreu e por não possuir antecedentes criminais e não repre sentar ameaça à sociedade; ela teve a pena suspensa. Ela não foi para a cadeia, contrariando o veredicto das opiniōes públicas publicadas.

O resultado surgiu com revolta, principalmente por negros e jovens. Para complicar situação, o julgamento dos policiais (a quem mídia já condenara) concluiu que eles eram inocentes. Sob grande impacto, personalidades políticos e líderes comunitários expuseram insatisfação com a impunidade na mídia e insuflaram a população a se posicionar diante do quadro produzido.
Em poucas horas as ruas ocuparam-se de distúrbios. À polícia não bastava acusar a mídia ou responsabilizar os quatros policiais envolvidos no espancamento do rapaz. O controle da situação se deu de forma muito problemática e difícil.

A análise dos fatos e da cobertura que receberam, mais tarde, apontou erros de toda as partes. A mídia agiu irresponsavelmente incitando manifestações populares e até fazendo emissões ao vivo de áreas sem policiamento, convocando (mesmo que involuntariamente) criminosos a agir livremente sem a presença do Estado e da lei. No entanto, contrastando as imagens de televisão e as fotografias de mídia impressa com os dados policiais, percebe-se que houve desvios. A polícia e a imprensa trataram dos distúrbios como sendo provocados unicamente por revolta à impunidade e à postura policial em relação aos negros. $\mathrm{E}$ as imagens mostram que os distúrbios com saques ocorreram no primeiro dia em bairros de classe média não necessariamente negra, em lojas de bebidas e cigarros. Só no segundo dia, depois de repercussão dos meios de comunicação, houve maior partici pação de latinos (classe mais pobre) e saques indiscriminados: maior tumulto. Portanto, a revolta da comunidade negra proporcionou distúrbios, mas não a maioria nem os primeiros. Rodney King não era a motivação dos tumultos.

\section{Seqüestro ao 174}

Já o caso da transmissão do seqüestro ao ônibus da linha 174 (Gávea-Central) feito po canais de televisão aberta e por assinatura. $\mathrm{E}$ transmitido ao vivo. Todos aqueles que estavam de frente para um aparelho televisor na segunda dia 12 puderam acompanhar simultaneamente o drama vividos pelas pessoas que estavam no ônibus. Quem viu ao vivo na TV o ocorrido pôde, sem dúvida, imaginar-se naquela situação.

${ }^{5}$ Termo cunhado por Habermas. 
Um dia antes do incidente ocorrido na rua Jardim Botânico, vinte mulheres sofreram ataques sexuais de um grupo de setenta a oitenta homens, porto-riquenhos, comemorando o dia de Porto Rico no Central Park, em Nova Iorque ${ }^{6}$. A polícia, mesmo nas ruas devido às comemorações do dia, demorou três horas para socorrer as vítimas e intervir na situação de pânico que se criou no local. A notícia ganhou grande destaque no dia seguinte. Uma semana depois, ninguém falava do assunto.

O seqüestro promovido por Sandro do Nascimento, ganhou destaque durante mais de uma semana, provocou mudanças nas políticas de segurança pública do Estado e do país e gerou discussões que ainda não terminaram a propósito da situação atual de violência nas grandes cidades.

Para entender a diferença entre os dois casos, basta analisar o comportamento da mídia nos dois acontecimentos. No caso nova-iorquino, a imprensa não criou vínculos entre as vítimas $\mathrm{e}$ os receptores. Não havia entre as mulheres atacadas, pelo menos não na abordagem dos meios de comunicação, uma Geisa: moradora da favela, professora de criancinhas, nordestina, com sonhos de crescer na vida. A imprensa também não pôde criar um supervilão desvairado, já que além de muitos, os criminosos pertenciam a uma minoria social (imigrantes porto-riquenhos). Não se consideram garotos de rua minoria por que eles não têm discurso próprio, não têm representantes com poder formador de opinião. Consideram-se excluídos.

Assim, apenas o caso carioca possui im portância para uma análise de comportamento da imprensa no julgamento de um acontecimento. O seqüestro do ônibus foi espetacularizado, ganhou um tratamento digno de filme. Na TV Record, a cobertura jornalística ganhou trilha

sonora. No portal da Internet Globo.com a chamada do vídeo confundia-se com um anúncio de 'próximas atrações' de Tela Quente: “Assista aqui cenas ao vivo do seqüestro do ônibus no Jardim Botânico". O uso da câmera de vídeo em closes lentos com narrativas às vezes em off carregadas de emoção e nervosismo provocava suspense no espectador. O interesse na busca pela informação, devido à concorrência entre canais de comunicação provocou ênfase na audiência, na geração de um entretenimento macabro para quem estivesse acompanhando os fatos torcendo contra o bandido por um desfecho feliz.

Assim, o que pode-se observar é uma espetacularização da violência por parte da mídia. Esta espetacularização contribui com a superficialidade da discussão sobre violência promovida pela mídia, já anteriormente remarcada. Por exemplo, não se viu na mídia uma discussão sobre as condições sociais que levam uma pessoa a agir com Sandro do Nascimento agiu. Ao contrário, o que se viu foi uma insistência no ponto da estrutura policial (não menos válido).

E esta insistência também dá ao assunto um tratamento superficial, uma vez que deixa de lado várias outras questões talvez até mais importantes, tais como a falta de uma formação humana da polícia e o continuísmo de certas práticas do autoritarismo político. Quanto à formação humana, esta era essencial no caso do seqüestro, uma vez que a polícia militar não conta com negociadores especializados. Quanto às práticas do autoritarismo político, 0 melhor exemplo foi o assassinato de Sandro por parte dos policiais. Os policiais atuam como se eles ainda - isto porque na época da ditadura militar, o Bope atuava realmente acima da lei - estivessem a cima da lei.
A função política da polícia fica clara nesta situação. Ela não atua como mantenedor da segurança dos cidadãos. Sua função maior é manter o crime longe de bairros como o Jardim Botânico (onde, como já dissemos, o crime é uma anomalia). Mais do que isto, a polícia deve neutralizar os sujeitos capazes de gerar o crime, os considerados marginais. Isto abre precedentes para o preconceito e demonstra o autoritarismo que paira sobre nossa sociedade. Voltemos à questão do espetáculo jornalístico. O professor de Semiologia Umberto Eco descreve desta forma a estrutura desta espetacularização:

E os diários? Para se tornarem semanais aumentam o número de páginas, para aumentálo lutam por publicidade, para ter publicidade aumentam ainda mais as páginas e inventam suplementos, para ocupar todas essas páginas são obrigados a contar alguma coisa, para in ventar algo devem ir além da notícia seca (que, aliás, já foi dada pela televisão) e, portanto, "semanalizam-se" cada vez mais e têm que in ventar notícia, e transformar em notícia o que não é notícia ${ }^{7}$.

Pois bem, de uma maneira ou de outra, o caso do ônibus 174 é notícia. Por que? Isto envolve muitos fatores, que vão desde o fato de o caso ter ocorrido no Jardim Botânico, bairro de classe média-alta do Rio de Janeiro, até a curiosidade do público quanto ao desfecho do ocorrido.

Quanto ao local em que ocorreu o seqüestro, há ainda algumas considerações a fazer. Basicamente, são três os motivos que fazem a notícia merecer maior repercussão nos meios de comunicação. Primeiramente, ele ocorreu num bairro rico, de classe-média alta. Isto influ muito, ainda mais se levarmos em conta a forte hierarquização da sociedade brasileira. Esta hierarquização faz com que os bairros onde moram as classes mais altas tornem-se "mundos à parte", onde o crime é considerado uma anomalia - diferentemente dos bairros mais pobres, onde o crime é uma normalidade.

O segundo motivo pelo qual o seqüestro ganha repercussão é de cunho geográfico. O Jardim Botânico é um dos muitos bairros no Rio que são chamados de bairros de passagem - e dentre estes bairros ele certamente ocupa destaque por ser a passagem das camadas mais altas da sociedade. Ora, o ocorrido na rua Jardim Botânico causou, como se viu, um grande caos no trânsito, ou seja, na circulação da área, atrapalhando a vida de muita gente - em sua maioria de classe média para cima - e aumentando a repercussão do caso.

O terceiro motivo para a grande repercussão que vamos ressaltar é menos evidente, mas ainda assim tem sua importância. $O$ seqüestro ocorreu quase em frente do prédio das Organizações Globo, a maior empresa de mídia do país. Ou seja, para que este caso de violência fosse flagrado ao vivo, bastava aos cinegrafistas que descessem do prédio munidos de câmeras.

\section{VIOLÊNCIA E SEGURANÇA PÚBLICA}

A sociedade brasileira vive hoje dramá tico dilema: confia cada vez menos nos organismos policiais encarregados de protegê-la e, ao mesmo tempo, se sente cada vez mais ameaçada pela delinqüência urbana. Recentes episódios têm mostrado para milhões de telespectadores o que as pesquisas públicas já expressavam em números: menos de $10 \%$ da população confia na polícia.

As filmagens de espancamentos, mortes e humilhações indignam o país, onde existe $o$ 
consenso de que tais incidentes são rotineiros nos bairros pobres.

O problema é mais crítico num contexto em que a opinião pública reclama mais segurança contra a delinqüência alimentada pela miséria, enquanto os governos contam com recursos cada vez menores.

Várias pesquisas são feitas, principalmente em cidades como o Rio de Janeiro e São Paulo, e revelam que mais de $70 \%$ dos entrevistados têm medo de ser assaltados, mas mais de $60 \%$ não avisariam a polícia se fossem, por temer serem presos. Conclusão: o povo não só tem medo de ladrão como de polícia também.

O porquê desse medo vem das mortes causadas pela polícia civil e militar, várias delas ocorrendo em casos de resistência a prisão outras com direito a torturas.

Boa parte desses homicídios não acontece por acidente, em caso de legítima defesa ou em situação de enfrentamento, como depois aparece nos relatórios policiais, mas faz parte de uma estratégia ou método de "controle da criminalidade" adotado pelos nossos órgãos de segurança. Tanto é que, nos ditos confrontos, número de mortos ou feridos entre os civis cerca de dezesseis vezes maior do que as baixas policiais.

O pior é que nem todos os cidadãos mortos cometeram algum delito. Ao contrário, em sua maioria, estavam apenas tentando, e, em alguns casos, foram só considerados suspeitos em função da postura ou da aparência. Nesse último caso, as classes despossuídas e os negros são as maiores vítimas, já que fazem parte do segmento da população considerado criminalizável.

Surpreendentemente, num país que carrega os rótulos de bagunçado e desordeiro, a cada dia cresce a eficiência do "crime organizado", ou seja, atividades de grupos com determnado grau de organização, especialização, tecnologia e poder ligados ao tráfico de drogas, jogo de bicho, roubo de carros, furto de armas, falsificação de documentos, tortura, assassinatos e desaparecimento de cadáveres.

Esse crime vem se apresentando como $\mathrm{m}$ fato tanto mais sério quanto mais se tem revelado, em seu meio, a partici pação de delegados, investigadores, escrivães de polícia e guardas de presidio, envolvidos também com os chamados "crime de aluguel", quando então se associam a criminosos comuns e matadores profissionais e cometem assassinatos em troca de dinheiro.

Nos meios de comunicação nem sempre se dá o devido destaque ao fato, aparecendo em primeiro plano os subordinados e testasde-ferro civis mais do que os mandantes ou chefes policiais.

A população dos morros, em muitas asiōes, vem se colocando mais favoravelmente ao lado dos marginais porque deles recebem benfeitorias, transportes em caso de emergên cia apoio financeiro e, até mesmo (e isso mais parece ironia), proteção contra os policiais. Estes sim, muitas vezes, são vistos como inimigos.

"A alegação dos policiais é de que o disparo foi feito durante a perseguição. A família sustenta que houve execução". Notícias como essa tornaram-se freqüentes nos jornais de hoje. É a palavra de uns contra a dos outros. Mas aqui vigora a lei da $\mathrm{PM}$.

A impunidade tem se tornado uma regra ditada pelos policiais. Os inquérito comum que as provas recolhidas sejam ar quivadas, invalidadas ou desfiguradas. $\mathrm{Ha}$ casos de PMs, que, quando foram conde- nados já nem estavam mais vivos e outros em que os crimes acabaram prescrevendo e os acusados não puderam mais ser julgados. A inexistência de critérios rígidos de punição e a falta de controle sobre a tropa dão margem aos atos de corrupção e violência que colocam em xeque o atual modelo de polícia militar. Os crimes praticados por esses policiais são os mesmos cometidos por bandidos comuns. Para eles, boa parte da PM reclama a pena de morte. No entanto, quando os bandidos usam farda como manto passam a ser criminosos privilegiados.

As vítimas dessa polícia bandida são em sua grande maioria pessoas pobres. $E$ os crimes têm como cúmplices a omissão da sociedade. Não chocam mais ninguém e as próprias famílias geralmente acabam acei tando o fato como o preço a pagar por viverem num país onde a falta de justiça parece crescer a cada dia.

As PMs são hoje forças autônomas, fora do controle dos governadores. Inquéritos são conduzidos para não dar em nada. Reconhecimentos são feitos sem qualquer proteção às vítimas.

Com a autoridade de quem já comandou os policiais, o ex-secretário de Segurança de São Paulo, Antônio Cláudio Mariz de Oliveira afirma que o problema reside no fato de a $\mathrm{PM}$ ser uma força incontrolável. "A Polícia Militar é um estado dentro do Estado".

O poder da PM é incontestável. Sabe-se que a corporação mantém um serviço secreto, a chamada P-2, que funciona como uma espécie de SNI. Mas a P-2 nunca divulga o que descobre a respeito da própria PM. As informações acumuladas pelo serviço secreto da Polícia Militar acabam se traduzindo em poder político.
Uma parte considerável das vítimas dos delitos não denuncia os policiais e, quando o faz, se arrepende por causa do tempo perdido e dos inconvenientes que a denúncia acarreta.

São comuns depoimentos como esses: "Desde que fiz a denúncia passei a ser ameaçada. Vivo com medo."; "Apanhei e agora não me sinto seguro sequer para dizer quem me bateu"; "A última coisa que um cidadão deseja é chamar a polícia, pois sabe que com ela chega também a insegurança".

Cenas de violência policial têm sido exibidas cada vez com mais frequiência na tela de tevê comovendo os telespectadores. Muitas vozes que defendiam com veemência a truculência policial passaram a mostrar indignação com as barbáries cometidas por policiais e quebrar períodos de silêncio.

E para encorajar essas vozes, os meios de comunicação têm possibilitado que a população denuncie. Alguns mecanismos como o "Disque Denúncia" estão sendo criados e postos em prática. Através deles, as pessoas estão tendo a possibilidade de telefonarem denunciando suspeitos sem correrem o risco de serem identificadas. Além disso, propagandas estão sendo anunciadas o tempo todo pela mídia incentivando as denúncias.

Diante de tantas denúncias, o governo vê-se obrigado a tomar providências e apressar respostas à opinião pública. Várias questões já foram levantadas como: aumento de salários, integração da polícia com cada bairro, policiamento nas ruas, desarmamento policial, melhor formação dos policiais, desmilitarização da PM, julgamentos na justiça comum... Todos acham que a polícia deve mudar, mas não tem sido fácil chegar a um consenso sobre como torná-la eficiente e civilizada. 
A violência está presente de maneira significativa no imaginário social da população brasileira, desconstruindo a falsa idéia de que o Brasil seria um país "pacífico por natureza". No interior do jogo social, a violência é praticada de forma bruta, gerando o caos ao qual geralmente é associada a criminalidade.

Pelo menos três modulações da violência encontram lugar no imaginário social. A primeira destas modulações seria a violência, normalmente ignorada, dos poderes instituídos com base legitimada. Ela é a mais constante e, ao mesmo tempo, a menos visível. A Segunda modulação é a violência vista como perspectiva de perpetuação de algum fator social. Sob tal ótica, sua base é normativa e estruturadora, procurando garantir a sobrevivência de determinada ordem ou estrutura social. Ocorre também, a modulação "moralista" da violência, a qual é fundamentada na destruição, o que faz com que ela seja apontada como a catalisadora da criminalidade social. Geralmente, esta é a visão de violência a qual impera no imaginário social e é associada a pobreza.

Uma visão mais positivista da violência, no sentido de construir novos sentidos de alteridade, parece ainda estar adormecida no imaginário dos atores sociais brasileiros. Uma leitura a qual apontasse para a associação da violência à conflitos traria novos sentidos, - significados renovando assim, o imaginário social. Isto incitaria o desenvolvimento de um maior crivo crítico, por parte dos atores sociais em questão, a fim de não mais aceitar a estilização, especialmente a midiática, a qual a violência é submetida.

É interessante perceber que ao associar a violência à pobreza, uma grande parcela da população brasileira a realiza como algo pelo qual não se sente responsável, no sentido de sentir-se culpada. Desta forma, assume o confortante papel de vítimas.

Tal parcela da população, a qual não se encaixa no perfil da pobreza, possui no imagi-
nário coletivo a premissa de que a sociedade moderna contemporânea está calcada no mito de que somos uma sociedade pacífica. A violência é por eles enxergada com um sentido negativo, de destruição, responsável pela deturpação desta sociedade, na qual impera a paz. É necessário ressaltar que nesta visão a violência é aprendida em sua modulação mais banalizada, na qual a luta é pensada como uma fato prejudicial a sociedade, quando esta luta é o fundamento de qualquer relação social. A violência "destrutiva" é a manifestação da afirmação individual no imaginário coletivo.

Cabe, então, a pergunta: como teria se formado este imaginário social coletivo sobre a violência? A ênfase da cobertura mediática de seus episódios somada ao intenso debate sobre a natureza e as consequiências deste aumento teriam gerado um excesso de tematização o qual teve o efeito de construir o citado imaginário.

\section{CONCLUSÃO}

Daí, o que se pode concluir é que a problemática da violência é algo muito mais complexo. O tratamento dado pela mídia à questão geralmente faz vista grossa a esta complexidade. A violência é algo tratado como uma simples questão de repressão, uma simples questão de polícia. Quando na verdade estamos lidando com algo muito mais profundo, que envolve questões políticas, de intolerância e preconceito, de estrutura social.

Quanto às políticas de combate à violência e à criminalidade, devemos sempre ressaltar a importância do papel da mídia neste processo. A mídia deve unir a sociedade em torno de políticas que atuem mais fundo na reestruturação das polícias, que devem ter seu papel político debatido sem tabus para que possamos construir uma nova polícia e um novo aparelho judicial. Estas reestruturações são essenciais para que a sociedade brasileira dê um passo em direção de uma cidadania mais com pleta. Enquanto antigas práticas políticas de privilégios e hierarquias forem mantidas em noss sociedade, o combate à violência e aos demai problemas sociais será complicado.

É também essencial que façamo reestruturações quanto à forma como a violência é tratada, não somente na mídia, mas em nossa sociedade com um todo. Historicamen te, a sociedade brasileira tem uma tendência se ver como um povo pacífico. Ultimamente sem dúvida devido, em grande parte, a influên cia da mídia - a sociedade brasileira tem se visto como uma das mais violentas do mundo. A violência, com certeza, está na ordem do dia.

Esta mudança na maneira de se olhar dá a impressão de que a violência é um fenômeno recente, coisa dos dias de hoje. Este mito deve ser dissolvido. Por isto nossa sociedade precisa fazer também um reexame histórico, com a partici pação ativa da mídia onde possamos buscar as raízes que molda ram nossa estrutura social atual. Precisamos mesmo fazer um exame de consciência que traga à tona todo o sangue derramado em vão em nossa violenta história.

Infelizmente, perdeu-se recentemente uma grande oportunidade de se fazer este reexame. $\mathrm{O}$ tratamento dado pela mídia ao aniversário de 500 anos do descobrimento do Brasil foi péssimo. Resolveu-se comemorar algo que nada tem de positivo. A mídia não abriu espaço algum para um discurso capaz de criticar esta posição, um discurso que demonstrasse todas as marcas violentas da dominação portuguesa que restam até os dias de hoje.
Cabe a nós ter a esperança de que num futuro não muito longínquo estas questões possam todas ser repensadas em con junto. Só assim seremos capazes de construir uma sociedade realmente nova, onde finalmente poderemos implementar o tal do Estado democrático de direito, que infelizmente hoje está só na teoria. Tais processos são fundamentais para que o combate à violência seja feito de uma maneira séria e para o benefício de todos.

\section{BIBLIOGRAFIA}

CERQUEIRA, Carlos Magno Nazareth. "O Comandante de uma Polícia Brasileira" in Mídia \& violência urbana. Rio de Janeiro, FAPERJ, 1994.

CERQUEIRA FILHO, Gisálio \& NEDER, Gizlene. "A violência na boca do povo" in Direito e Avesso. Ano II, n² 3, Brasília, Edições Nair, janeiro/julho 1983.

CERQUEIRA FILHO, Gisálio. "Estado de (in)segurança" in Folha de São Paulo, 20 de setembro de 1981

"Violência fora do vídeo" in $F O$ Iha de São Paulo, 16 de agosto de 1981.

ECO, Umberto. Cinco Escritos Morais. Rio de Janeiro, Ed. Record, 1998

FAUSTO NETO, Antônio. "Mídia tribunal - A construção discursiva da violência: o caso do Rio de Janeiro".

GAROTINHO, Anthony. Violência e Criminalidade no Estado do Rio de Janeiro - Diagnóstico e propostas para uma política democrática de segurança pública. Rio de Janeiro. Ed Hama. 1998

GASCON, David. "A Polícia de Los Angeles e os Distúrbios de Rua" in Mídia \& violência urbana, ibidem. 
MEFFESOLI, Michel. $A$ dinâmica da violência. São Paulo, Vértice, 1987.

MOTTA, Dilson \& MISSE, Michel. Crime o social pela culatra. Rio de Janeiro Achiamé, 1979.

RONDELLI, Elizabeth. "As imagens da violência"

\section{OUTRAS FONTES}

ABREU, Patrícia de. "Ver para crer" in Jornal do Brasil (coluna Ancora). 16/06/2000.
KRAMER, Dora. "Erro de pessoa" in Jornal do Brasil (coluna Coisas da política). 17/ 06/2000.

Revista Veja. São Paulo, Abril. Número 1654 - 21 de junho de 2000.

Revista Istoé. São Paulo, editora Três. Número 1603 - 21 de junho de 2000.

WWW.GLOBO.COM do dia 12 de junho de 2000.

Discursos de Anthony Garotinho e Fernando Henrique Cardoso no 53. Congresso de Jornais, realizado no Rio de Janeiro entre 10 e 14 de junho de 2000 .

\title{
O Projeto que Institui o Novo Código Civil Brasileiro
}

\author{
Carlos Silveira Moronha \\ Professor Titular de Direito Civil da UFRGS \\ Doutor em Direito pela USP
}

1 rans vigência, no Brasil, das Ordenações Fili pinas, promulgadas pelo Reino de Portugal em 1.603, os estudos para a edição de uma codificação nacional própria, destinada a reger as relaçōes civis, tiveram início com o anteprojeto Teixeira de Freitas a cerca de cento e cinqüenta anos, em 1859. Sucederam-no mais quatro tentativas de codificação (Nabuco de Araújo, em 1872; Felicio dos Santos, em 1881; Coelho Rodrigues, em 1893), que desaguaram no anteprojeto Clóvis Beviláqua, editando-se, com a aprovação deste, o atual Código, com a Lei no ${ }^{\circ} .071$, de $1^{\circ}$ de janeiro de 1916 , que vem regendo a vida da Nação a partir de $1^{\circ}$ de janeiro de 1.917.

Embora sem seguir exatamente a sua estrutura sistemática, a codificação civil moderna que mais influenciou o primeiro estatuto nacional foi a inaugurada com o Código Napoleão, de 1.804. O Código Civil Brasileiro de 1.916, tem sua estrutura sistemática composta de uma Parte Geral, dividida em três livros (pessoas, bens e fatos jurídicos) e de uma Parte Especial, dividida em quatro Livros (na seqüência, Direitos de Família, das Coisas, das Obrigações e das Sucessões). Este notável documento jurídico, complementado e modificado por uma abundante legislação extravagante, regeu com plena eficácia e proficiência as relações privadas dos súditos da Nação por qua- se todo o século XX, até que as profundas, radicais e positivas modificações na cultura política e jurídica pátrias, e bem assim as sensiveis alterações na organização social e no modelo econômico, submetidas, todas, a constante questionamento, não como sinal de crise, senão como indicativo da vitalidade da Nação, passaram a exigir uma profunda mudança na ordem civil.

Daí adveio a necessidade de renovar as instituições civis pátrias, que teve seu marco inicial no Governo João Goulart, por intermédio do seu Ministro da Justiça, João Mangabeira, encarregando o professor Orlando Gomes para elaborar um Projeto de Código Civil e o professor Caio Mário da Silva Pereira para projetar um Código de Obrigações.

Abandonando o critério da dualidade e optando pelo da unificação do direito privado, que teve início, entre nós, por Teixeira de Freitas, seguido por Carlos de Carvalho, Coelho Rodrigues, Inglez de Souza, Lacerda de Almeida e outros, o Governo retirou do Congresso Nacional, em 1966, os dois anteprojetos referidos (Pronunciamento do Senador Josaphat Marinho, Edição do Senado, 1997, págs. 20-21).

Em seguida, foi criada uma Comissão de eminentes juristas, sob a coordenação gera do Professor Miguel Reale, da Universidade de 